Rev. Bras. Saúde Prod. Anim., Salvador, v.16, n.1, p.36-46 jan./mar., 2015 http://www.rbspa.ufba.br ISSN 15199940

\title{
Desempenho de bovinos da raça Gir em pastagem de Brachiaria brizantha submetidos a diferentes manejos
}

\author{
Performance of Gir young bull maintained in "Brachiaria brizantha" pastures \\ submitted to different management
}
FERNANDES, Leonardo de Oliveira ${ }^{1 *}$; REIS, Ricardo de Andrade ${ }^{2}$; PAES, José Mauro Valente $^{1}$; TEIXEIRA, Rafael Monteiro Araújo ${ }^{3}$; QUEIROZ, Domingos Sávio ${ }^{4}$; PASCHOAL, Juliana Jorge ${ }^{5}$

\author{
${ }^{1}$ Empresa de Pesquisa Agropecuária de Minas Gerais, Uberaba, Minas Gerais, Brasil \\ ${ }^{2}$ Universidade Estadual Paulista, Faculdade de Ciências Agrárias e Veterinária, Departamento de \\ Zootecnia, Jaboticabal, São Paulo, Brasil \\ ${ }^{3}$ Instituto Federal de Educação, Ciência e Tecnologia do Triângulo Mineiro, Uberaba, Minas Gerais, Brasil \\ ${ }^{4}$ Empresa de Pesquisa Agropecuária de Minas Gerais, Viçosa, Minas Gerais, Brasil \\ ${ }^{5}$ Faculdades Associadas de Uberaba, Uberaba, Minas Gerais, Brasil \\ *Endereço para correspondência: leonardo@epamig.br
}

\section{RESUMO}

O objetivo com este trabalho foi avaliar o efeito da suplementação protéico-energética e diferentes ofertas de forragem (OF) durante o período das águas, sobre o ganho de peso de bovinos da raça Gir manejados em sistema de lotação rotacionada em Brachiaria brizantha cv. Marandu. Avaliou-se a disponibilidade e a composição química do capim Brachiaria brizantha cv. Marandu. Foram utilizados 24 bovinos da raça Gir com peso médio de $223 \mathrm{~kg}$, distribuídos em um delineamento em blocos ao acaso, em parcela subdividida, alocando os tratamentos nas parcelas e os períodos nas subparcelas, com quatro tratamentos e seis repetições. Os tratamentos foram: novilhos sem suplementação (SS) mantidos em pastos com $4,0 \%$ do peso corporal (PC) de OF (SS $+4,0 \%$ $\mathrm{OF})$; tourinhos suplementados (SO) com concentrado em $0,5 \%$ do peso corporal (PC) e $4 \%$ do PC de OF (SO $+4,0 \% \mathrm{OF}$ ); tourinhos suplementados com concentrado em $0,5 \%$ do $\mathrm{PC}$ e $3,5 \%$ do PC de OF (SO + 3,5\% OF) e tourinhos suplementados com concentrado em $0,5 \%$ do $\mathrm{PC}$ e $4,5 \%$ do $\mathrm{PC}$ de $\mathrm{OF}$ (SO + $4,5 \% \mathrm{OF})$. Foi verificado, durante o período das águas, aumento $(\mathrm{P}<0,05)$ no ganho de peso dos novilhos suplementados $(0,848,0,813 \quad \mathrm{e}$ $0,905 \mathrm{~kg} / \mathrm{dia}$, respectivamente nos tratamentos $\mathrm{SO}+4 \% \mathrm{OF} ; \mathrm{SO}+3,5 \% \mathrm{OF}$ e $\mathrm{SO}+4,5 \% \mathrm{OF}$ ) comparado aos novilhos que não receberam suplementação $(0,567 \mathrm{~kg} / \mathrm{dia})$. Os animais do tratamento $\mathrm{SO}+4,5 \% \mathrm{OF}$ apresentaram maior ganho comparados aos do $\mathrm{SO}+4 \% \mathrm{OF}$ e $\mathrm{SO}+$ $3,5 \% \mathrm{OF}$. Não houve efeito dos tratamentos sobre a composição química da forragem $(\mathrm{P}>0,05)$.

Palavras-chave: ganho de peso, gramínea tropical, pastejo rotacionado, suplemento

\section{SUMMARY}

This research aimed to evaluate the effect of protein and energy supplementation and different herbage allowances (OF) during the rainy season, on the weight gain of Gir young bulls grazing Brachiaria brizantha maintained in a rotational grazing system. Evaluated forage allowance and chemical composition of Brachiaria brizantha pasture. We used 24 Gir young bulls with an average weight of $223 \mathrm{~kg}$, distributed in a randomized block design in a split plot scheme, treatments was distributed in plots, and periods in subplots, with six replications. Treatments were not supplemented (SS) young bull grazing in pasture with $4.0 \%$ of forage allowance (SS + 4\% FA); supplementation with $0.5 \%$ body weight (SO) and $4.0 \%$ of FA (SO + $4.0 \%$ FA); supplementation with $0.5 \%$ body weight and $3.5 \%$ FA (SO $+3.5 \%$ FA) and supplementation with $0.5 \%$ body weight and $4.5 \%$ FA ( $\mathrm{SO}+4.5 \%$ FA). During the rainy season, the young bulls weight gain increased ( $\mathrm{P}$ $<0.05)$ in response to supplementation $(0.848$, 0.813 and $0.905 \mathrm{~kg} /$ day), respectively in the 
Rev. Bras. Saúde Prod. Anim., Salvador, v.16, n.1, p.36-46 jan./mar., 2015 http://www.rbspa.ufba.br ISSN 15199940

animals of the $\mathrm{S} 0+4 \% \mathrm{OF}$; $\mathrm{SO}+3.5$ and $\mathrm{SO}$ $\mathrm{OF} \% \mathrm{OF}+4.5$, compared to those not supplemented $(0.567 \mathrm{~kg} /$ day $)$. Animals of the $\mathrm{SO}+4.5 \%$ OF showed higher gain compared to the $\mathrm{SO}+4.0 \% \mathrm{OF}$ and $\mathrm{SO}+3.5 \% \mathrm{OF}$. Pasture management strategies and supplementation did not affect the forage chemical composition $(\mathrm{P}>0.05)$.

Keywords: rotational grazing, supplementation, tropical grass, weight gain

\section{INTRODUÇÃO}

A produção de bovinos de corte no Brasil está consolidada com o uso das pastagens, regida por duas estações bem definidas, seca e águas principalmente na região tropical do país (PORTO et al., 2009).

Para o período das águas as forrageiras tropicais, principalmente do gênero brachiaria apresentam teores médios de proteína bruta $(\mathrm{PB})$ que satisfazem as necessidades dos microrganismos, isto é, acima de $7 \%$ de $\mathrm{PB}$, valor considerado por Minson (1990) como limitante para atividade dos microrganismos do rúmen. Entretanto, essa atividade pode ser adequada apenas para a manutenção dos animais e compromete a digestibilidade de forragem altamente fibrosa (MATHIS et al., 2000).

Dessa forma, o uso da suplementação protéica-energética durante o período das águas pode ser viável quando se objetiva manter uma curva de crescimento contínua visando abates mais precoces. $\mathrm{O}$ uso de suplementação protéica-energética nas águas se explica pelo fato de que quando a forragem é de qualidade média ou boa, o fornecimento de suplementos ricos em energia pode gerar um tipo de interação com os microrganismos que induz um efeito negativo sobre o desaparecimento da fibra (DIXON \& STOCKDALE, 1999). Portanto, o atendimento das necessidades totais de proteína degradada no rúmen também deve ser avaliado (PAULINO et al., 2005).

É importante enfatizar que fatores nutricionais relacionados a qualidade da forragem não corrigem os problemas inerentes a sua disponibilidade (POPPI \& McLENNAN, 1995; MOORE et al., 1999). Sendo necessário na produção de bovinos sob pastejo um refinamento nas interações entre a quantidade de forragem ofertada e o tipo de suplementação utilizada. Pois, o desconhecimento dessas interações ou a falta de equilíbrio entre os fatores (forragem e suplementos) poderá alterar o resultado planejado (REIS et al., 2009).

O objetivo deste trabalho foi verificar a disponibildade e a composição química da Brachiaria brizantha cv. Marandu ao longo do período das águas e avaliar o efeito da suplementação protéicoenergética e diferentes ofertas de forragem sobre o ganho de peso de bovinos da raça Gir manejados em sistema de lotação rotacionada.

\section{MATERIAL E MÉTODOS}

O trabalho foi conduzido de novembro de 2010 a abril de 2011, na Fazenda Experimental Getúlio Vargas, unidade de pesquisa da EPAMIG - Empresa de Pesquisa Agropecuária de Minas Gerais, no município de Uberaba/MG, localizada a $19^{\circ} 45^{\prime} 56^{\prime \prime}$ de latitude sul e $47^{\circ} 57^{\prime}$ de longitude oeste, numa altitude de $774 \mathrm{~m}$. O clima da região é do tipo tropical semi-úmido e a temperatura média é de $21,4^{\circ} \mathrm{C}$. A precipitação anual média é de $1684,6 \mathrm{~mm}$ e a umidade relativa do ar é de 71,4\%, dados obtidos na Estação Climatológica Principal de Uberaba (EPAMIG/INMET, 2014). As condições climáticas verificadas durante o período experimental podem ser observadas na Tabela 1. 
Rev. Bras. Saúde Prod. Anim., Salvador, v.16, n.1, p.36-46 jan./mar., 2015 http://www.rbspa.ufba.br ISSN 15199940

Tabela 1. Condições climáticas observadas durante o período experimental

\begin{tabular}{lccccccc}
\hline Condições & $10 / 2010$ & $11 / 2010$ & $12 / 2010$ & $01 / 2011$ & $02 / 2011$ & $03 / 2011$ & $04 / 2011$ \\
Climáticas & 176,4 & 359,0 & 226,3 & 284,7 & 188,1 & 629,1 & 301,2 \\
PP $(\mathrm{mm})$ & 23,4 & 23,3 & 24,8 & 24,1 & 24,4 & 23,0 & 22,8 \\
\hline
\end{tabular}

Fonte: Estação Climatológica Principal de Uberaba - EPAMIG/INMET (2014).

$\mathrm{PP}=$ precipitação pluviométrica; $\mathrm{TM}=$ temperatura média.

Foram utilizados 24 bezerros da raça Gir, com idade de 16 meses, peso médio inicial de $223 \mathrm{~kg}$. No início do período experimental os animais foram desverminados, vacinados, identificados individualmente, e em seguida, passaram por um processo de adaptação por 14 dias, sendo mantidos por 139 dias na pastagem de capim Brachiaria brizantha cv. Marandu.

Durante todo o experimento foram feitos os controles rotineiros de ectoparasitos e as desverminações necessárias, sendo as pesagens procedidas a cada ciclo de pastejo (em média 35 dias), após jejum completo de 14 horas. Foi fornecido sal mineral durante o período experimental com os seguintes níveis de garantia por $\mathrm{kg}$ do produto: $120 \mathrm{~g} \mathrm{Ca}, 82 \mathrm{~g}$ de $\mathrm{P}, 15 \mathrm{~g}$ de $\mathrm{Mg}, 121 \mathrm{~g} \mathrm{Na}, 2,2 \mathrm{~g}$ de S, 130mg de Co, 1160mg de $\mathrm{Cu}, 1120 \mathrm{mg}$ de F, $120 \mathrm{mg}$ de I, $1325 \mathrm{mg}$ de $\mathrm{Mn}, 33 \mathrm{mg}$ de $\mathrm{Se}$, e 4670mg de $\mathrm{Zn}$.

A área experimental possui solo classificado como Latossolo Vermelho Distrófico, textura Franco Arenosa, sendo constituída de 9,6 ha de capim Marandu divididos em doze piquetes. Cada piquete foi dividido em 6 subpiquetes, manejados pelo método de lotação rotacionada.

Conforme os dados da análise de solo da área (Tabela 2) foram realizadas as correções e adubações de manutenção. As adubações foram realizadas ao longo do período das águas, observando a quantidade de extração de nutrientes para a produção de matéria seca. Foram aplicados $1.000 \mathrm{~kg} / \mathrm{ha}$ de calcário dolomítico para elevar a saturação de bases em $60 \%$, no final do período da seca de 2010 e utilizados $50 \mathrm{~kg} / \mathrm{ha}$ de F.T.E. BR - 12 (9\% de Zn; $1,8 \%$ de B; $0,8 \%$ de $\mathrm{Cu} ; 3,0 \%$ de $\mathrm{Fe} ; 2,0 \%$ de $\mathrm{Mn}$ e $0,1 \%$ de Mo), $300 \mathrm{~kg} /$ ha de $\mathrm{N}, 90 \mathrm{~kg} / \mathrm{ha}$ de $\mathrm{P}_{2} \mathrm{O}_{5}$ e $300 \mathrm{~kg} / \mathrm{ha}$ de $\mathrm{K}_{2} \mathrm{O}$. A adubação com $\mathrm{N}$ e $\mathrm{K}_{2} \mathrm{O}$ foi parcelada em quatro aplicações, imediatamente após a saída dos animais dos piquetes. A adubação com fósforo foi realizada em novembro de 2010.

Tabela 2. Resultados da análise do solo na camada de 0 a $20 \mathrm{~cm}$

\begin{tabular}{|c|c|c|c|c|c|c|c|c|c|c|c|}
\hline $\mathrm{pH}$ & $\mathrm{P}^{1} \quad \mathrm{~K}$ & $\mathrm{Ca}$ & $\mathrm{Mg}$ & $\mathrm{H}+\mathrm{Al}$ & SB & CTC & V & Areia & Limo & Argila & $\mathrm{MO}$ \\
\hline $\mathrm{H}_{2} \mathrm{O}$ & $\mathrm{mg} / \mathrm{dm}^{3}$ & & & $\mathrm{molc} / \mathrm{c}$ & & & & & $\%$ & & $\mathrm{Dag} / \mathrm{dm}^{3}$ \\
\hline 5,4 & $2,5 \quad 90,0$ & 1,3 & 0,5 & 2,6 & 2,0 & 4,6 & 43,8 & 66,0 & 11,0 & 23,0 & 1,7 \\
\hline
\end{tabular}

Para cada conjunto de piquetes em pastejo rotacionado, foi adotado, durante a época das águas, manejo que proporcionou 6 dias de ocupação e 30 dias de descanso. Desta forma a pastagem foi manejada objetivando 
atingir altura de entrada de $25 \mathrm{~cm} \mathrm{e}$ altura de saída entre $15 \mathrm{~cm}$. A oferta de forragem planejada foi calculada, considerando a forragem colhida, cortando-se a forragem rente ao solo.

Para ajustar a oferta de forragem, os bovinos "testers" foram acompanhados por outros animais, quando necessário, no sistema "put and take".

Foram avaliados os seguintes tratamentos experimentais: $\mathrm{SS}+4 \% \mathrm{OF}$ - Bovinos mantidos em capim Marandu, manejados com lotação rotacionada $\mathrm{e}$ oferta de forragem de $4 \%$ do PC em matéria seca, sem suplementação de concentrado; S0,5\% + 4\%OF - Bovinos mantidos em capim Marandu, manejados com lotação rotacionada e oferta de forragem de 4\% do PC em matéria seca, com suplementação de concentrado em $0,5 \%$ do $\mathrm{PC} ; \mathrm{S} 0,5 \%+3,5 \% \mathrm{OF}-$ Bovinos mantidos em capim Marandu, manejados com lotação rotacionada $\mathrm{e}$ oferta de forragem de $3,5 \%$ do PC em matéria seca, com suplementação de concentrado $0,5 \%$ do $\mathrm{PC} ; \mathrm{S} 0,5 \%+$ 4,5\%OF - Bovinos mantidos em capim Marandu, manejados com lotação rotacionada e oferta de forragem de 4,5\% do PC em matéria seca, com suplementação de concentrado $0,5 \%$ do PC.

A suplementação foi formulada para ganho de peso estimado de 1,0kg/animal $/$ dia (Tabela 3). Os suplementos foram fornecidos em cochos coletivos na pastagem, uma vez ao dia (10 horas), com o objetivo de não interferir no pastejo durante o período da manhã (pico de pastejo). O suplemento utilizado possuía a seguinte composição: $70,9 \%$ de milho grão; $8,5 \%$ de farelo de soja; $13,6 \%$ de farinha de glúten de milho (glutenose); $4,1 \%$ de uréia; $0,4 \%$ de sulfato de amônio; $1,5 \%$ de fosfato bicálcico e $1,0 \%$ de melaço em pó.

Tabela 3. Composição químico-bromatológica do capim Marandu e do suplemento utilizado em \% da MS

\begin{tabular}{lcc}
\hline Itens & Forragem & Suplemento \\
\hline Matéria seca & 22,3 & 90,9 \\
Proteína bruta & 10,1 & 30,1 \\
Fibra em detergente neutro & 67,2 & 12,3 \\
Fibra em detergente ácido & 32,3 & 5,9 \\
Celulose & 28,0 & - \\
Hemicelulose & 34,9 & 6,4 \\
Lignina & 3,7 & - \\
\hline
\end{tabular}

A oferta de forragem foi avaliada através de corte em $0,5 \%$ da área total do piquete e pesagem do material. A escolha da área a ser amostrada foi feita aleatoriamente, sendo efetuados seis cortes rente ao solo de $1,0 \times 1,0 \mathrm{~m}$ no momento da entrada dos animais nos piquetes. Também foi efetuado $\mathrm{o}$ pastejo simulado, na saída dos bovinos dos piquetes.
As amostras de forragem para as análises laboratoriais foram colhidas no momento da avaliação de forragem, através de pastejo simulado, em cada mudança dos bovinos de piquetes, perfazendo uma amostra composta a cada ciclo de pastejo.

As amostras recolhidas durante a avaliação da oferta de forragem e as amostras dos suplementos foram encaminhadas para o laboratório de 
Rev. Bras. Saúde Prod. Anim., Salvador, v.16, n.1, p.36-46 jan./mar., 2015 http://www.rbspa.ufba.br

forragicultura da UNESP/Jaboticabal. Foram determinados os teores de matéria seca (MS), proteína bruta (PB), fibra em detergente neutro (FDN), fibra em detergente ácido (FDA), celulose, hemicelulose, lignina e digestibilidade in vitro da matéria seca (DIVMS) conforme Silva \& Queiroz (2006), conforme apresentado na Tabela 3.

$\mathrm{O}$ delineamento utilizado para a avaliação do desempenho animal foi em blocos ao acaso (bloco $=$ conjunto de piquetes do sistema de pastejo rotacionado) em parcela subdividida. $\mathrm{Na}$ parcela foram alocados os tratamentos e nas subparcelas os períodos de avaliação. Foram utilizados quatro tratamentos com 6 repetições (duas por bloco). As médias foram comparadas pelo teste de Tukey a 5\% de probabilidade. Desta maneira podese manter em cada módulo (bloco, conjunto de seis piquetes) dois animais de cada tratamento.
$\mathrm{Na}$ avaliação dos dados da pastagem foi utilizado um delineamento em blocos ao acaso com quatro tratamentos e três repetições (bloco $=$ conjunto de piquetes do sistema de pastejo rotacionado).

\section{RESULTADOS E DISCUSSÃO}

Observou-se efeito do período de avaliação $(\mathrm{P}<0,05)$ para altura, densidade e disponibilidade de matéria seca por hectare em cada período (Tabela 4). Também foi observado maior disponibilidade de matéria seca no final do período de avaliação. A forragem apresentou maior altura nos períodos iniciais, diminuindo no final do período de avaliação. Já a densidade de forragem apresentou maiores valores no final do período de avaliação, o que pode ser justificado pela diminuição da altura da forragem e o aumento na matéria seca disponível neste período.

Tabela 4. Altura, densidade, taxa de acúmulo de forragem, disponibilidade de matéria seca por hectare em cada período (DMSP/ha) do capim Brachiaria brizantha cv. Marandu em função dos períodos

\begin{tabular}{lcccc}
\hline Períodos & $\begin{array}{c}\text { Altura } \\
(\mathrm{cm})\end{array}$ & $\begin{array}{c}\text { Densidade } \\
(\mathrm{kg} \mathrm{MS} / \mathrm{cm})\end{array}$ & $\begin{array}{c}\text { Taxa de acúmulo } \\
(\mathrm{kg} \mathrm{MS} / \mathrm{ha} / \mathrm{dia})\end{array}$ & $\begin{array}{c}\text { DMSP } \\
(\mathrm{kg} / \mathrm{ha})\end{array}$ \\
\hline $17 / 11 / 10-17 / 12 / 10$ & $34,9^{\mathrm{ab}}$ & $92,0^{\mathrm{b}}$ & $109,0^{\mathrm{a}}$ & $3.280^{\mathrm{c}}$ \\
$18 / 12 / 10-17 / 01 / 11$ & $39,2^{\mathrm{a}}$ & $93,1^{\mathrm{b}}$ & $117,0^{\mathrm{a}}$ & $3.734^{\mathrm{bc}}$ \\
$18 / 01 / 11-25 / 02 / 11$ & $31,7^{\mathrm{bc}}$ & $153,0^{\mathrm{a}}$ & $125,0^{\mathrm{a}}$ & $4.750^{\mathrm{ab}}$ \\
$26 / 02 / 11-05 / 04 / 11$ & $27,5^{\mathrm{c}}$ & $174,0^{\mathrm{a}}$ & $128,0^{\mathrm{a}}$ & $4.872^{\mathrm{a}}$ \\
\hline CV $(\%)$ & 18,0 & 24,5 & 34,1 & 33,4 \\
\hline a,b,c Médias seguidas de mesma \\
$\begin{array}{l}\text { probabilidade. } \\
\text { letra }\end{array}$
\end{tabular}

A disponibilidade de matéria seca total média foi de $16.635 \mathrm{~kg} / \mathrm{ha}$, caracterizando $\mathrm{o}$ alto potencial de produção da Brachiaria brizantha cv. Marandu, com média mensal de $3.327 \mathrm{~kg} / \mathrm{ha}$. Essa observação comprova que sistemas de pastejo rotacionado em capim Marandu, adubados e bem manejados são capazes de produzir alta quantidade de massa seca. Contudo, a alta oferta de forragem sem ajuste na taxa de lotação significa redução na capacidade produtiva do sistema de produção. De acordo com Braga et al. (2006) trabalhando vários níveis de oferta do capim Marandu, este apresentou media de produção de forragem de $4.070 \mathrm{~kg} /$ ha no pré-pastejo quando trabalhado numa oferta de $5 \%$ 
do peso vivo animal. Já em ofertas maiores a produção de forragem foi maior, mas observou-se dificuldades na capacidade de controlar as alturas de entrada e saída adequadas ao índice de interceptação luminosa do pasto, o qual implicou em perdas de forragem.

Euclides et al. (2008) ao avaliarem o efeito do pastejo sobre a produção de forragem, verificaram produções de matéria seca de $3.730 \mathrm{~kg} / \mathrm{ha}$ no prépastejo para o capim Brachiaria Brizantha cv. Marandu, valor inferior ao observado para o capim Brachiaria Brizantha cv. Xaraés $(4.075 \mathrm{~kg} / \mathrm{ha})$

Com relação a composição química da forrragem foi observado efeito de período $(\mathrm{P}<0,05)$ na variação da composição química (Tabela 5), fato que pode estar associado às diferenças climáticas entre os períodos de avaliação. De acordo com os dados da Tabela 1 verifica-se que a média de precipitação para os meses de fevereiro, março e abril foi por volta de $110 \mathrm{~mm}$ acima da média dos meses anteriores. Dessa forma, a quantidade de chuva provavelmente favoreceu o aparecimento de folhas novas, verificado pelo aumento da densidade de forragem, o que melhora a composição bromatológica do capim marandu. Essa melhora na composição bromatológica é constatada pelo aumento no conteúdo de $\mathrm{PB}$ e redução no conteúdo de FDN e FDA nos períodos finais de avaliação.

Tabela 5. Matéria seca (MS), proteína bruta (PB), fibra em detergente neutro (FDN) fibra em detergente ácido (FDA), hemicelulose (HEM.), celulose (CEL.), lignina (LIG.) e digestibilidade in vitro da matéria seca (\% da MS) do capim Brachiaria brizantha cv. Marandu em função dos períodos

\begin{tabular}{lcccccccc}
\hline \multirow{2}{*}{ Período } & MS & PB & FDN & FDA & HEM. & CEL. & LI. & DIVMS \\
\cline { 2 - 8 } & & \multicolumn{7}{c}{$\%$ da MS } \\
\hline $17 / 11-17 / 12 / 10$ & $23,6^{\mathrm{a}}$ & $8,4^{\mathrm{b}}$ & $69,1^{\mathrm{a}}$ & $34,6^{\mathrm{a}}$ & $34,5^{\mathrm{b}}$ & $30,8^{\mathrm{a}}$ & $3,8^{\mathrm{a}}$ & $64,3^{\mathrm{a}}$ \\
$18 / 12-17 / 01 / 11$ & $19,1^{\mathrm{c}}$ & $9,1^{\mathrm{b}}$ & $70,7^{\mathrm{a}}$ & $33,0^{\mathrm{b}}$ & $37,6^{\mathrm{a}}$ & $26,2^{\mathrm{b}}$ & $3,8^{\mathrm{a}}$ & $65,1^{\mathrm{a}}$ \\
$18 / 01-25 / 02 / 11$ & $21,7^{\mathrm{b}}$ & $12,0^{\mathrm{a}}$ & $62,4^{\mathrm{c}}$ & $29,7^{\mathrm{c}}$ & $32,7^{\mathrm{b}}$ & $26,6^{\mathrm{b}}$ & $3,5^{\mathrm{a}}$ & $66,3^{\mathrm{a}}$ \\
$26 / 02-05 / 04 / 11$ & $24,7^{\mathrm{a}}$ & $11,3^{\mathrm{a}}$ & $66,6^{\mathrm{b}}$ & $31,8^{\mathrm{b}}$ & $34,8^{\mathrm{b}}$ & $28,4^{\mathrm{ab}}$ & $3,5^{\mathrm{a}}$ & $65,9^{\mathrm{a}}$ \\
\hline CV (\%) & 10,4 & 10,6 & 4,1 & 5,7 & 8,1 & 15,0 & 31,1 & 23,4 \\
\hline
\end{tabular}

Médias seguidas de mesma letra na coluna, não diferem pelo teste de Tukey a $5 \%$ de probabilidade.

A DIVMS não apresentou alteração em relação aos períodos avaliados. A medida que aumentou a concentração de $\mathrm{PB}$ e reduziu a concentração de FDN e FDA no capim marandu ao longo dos períodos avaliados era de se esperar um aumento na digestibilidade do capim. Essa teoria não se concretizou provavelmente em função do teor de PB do capim estar acima de um mínimo ideal para as bactérias ruminais. Pois segundo Van Soest (1994), níveis protéicos dietéticos de 6 a $8 \%$, com base na MS, são necessários para que haja o fornecimento de compostos nitrogenados para os suprimentos das exigências microbianas, sendo que níveis inferiores a estes comprometem a digestibilidade da fibra. E de acordo com Lazzarini et al. (2009) observa-se incremento na digestibilidade quando o teor de $\mathrm{PB}$ da dieta aumenta até o nível de $7 \%$, acima deste valor geralmente observa-se uma estabilidade sugerindo uma resposta do tipo linear-reponse-plateau (LRP).

De acordo com os tratamentos utilizados, os animais que receberam a suplementação protéica-energética iniciaram o experimento consumindo por volta de $1,1 \mathrm{~kg}$ de suplemento concentrado 
e encerraram o experimento consumindo por volta de $1,7 \mathrm{~kg}$ de suplemento concentrado. Assim, a média de consumo diário de suplemento concentrado foi de $1,4 \mathrm{~kg} / \mathrm{animal}$, não sendo diferente entre os tratamentos que receberam suplementação protéica-energética, já que iniciaram e terminaram o experimento com peso vivo próximos.

Foram observadas diferenças no ganho de peso vivo médio diário entre os tratamentos $(\mathrm{P}<0,05)$, sendo verificados ganhos de peso de $0,567,0,848,0,813$ e $0,905 \mathrm{~kg} /$ novilho$/$ dia respectivamente para os tratamentos SS $+4 \% \mathrm{OF}, \mathrm{S} 0,5 \%+$ $4 \% \mathrm{OF}, \mathrm{S} 0,5 \%+3,5 \% \mathrm{OF}$ e $\mathrm{S} 0,5 \%+$ 4,5\%OF (Tabela 6). Ao comparar animais suplementados e não suplementados, observa-se de forma geral desempenho superior aos animais suplementados. Onde o uso de suplemento concentrado para uma mesma oferta de forragem $(4 \%)$ possibilitou um incremento no ganho de peso de $0,281 \mathrm{~kg} /$ novilho $/$ dia.

Tabela 6. Peso vivo inicial (PVI), peso vivo final (PVF), ganho de peso no período (GPP), ganho médio diário (GMD), ganho de peso/ha no período total (GPT/ha) e taxa de lotação (UA/ha)

\begin{tabular}{lcccccc}
\hline Tratamentos & $\begin{array}{c}\text { PVI } \\
(\mathrm{kg})\end{array}$ & $\begin{array}{c}\text { PVF } \\
(\mathrm{kg})\end{array}$ & $\begin{array}{c}\text { GPP } \\
(\mathrm{kg})\end{array}$ & $\begin{array}{c}\text { GMD } \\
(\mathrm{kg})\end{array}$ & $\begin{array}{c}\text { GPT/ha } \\
(\mathrm{kg})\end{array}$ & $\begin{array}{c}\text { Taxa de lotação } \\
(\mathrm{UA} / \mathrm{ha})\end{array}$ \\
\hline SS + 4\%OF & 220 & 298 & 79 & $0,567^{\mathrm{c}}$ & $865^{\mathrm{c}}$ & $6,4^{\mathrm{b}}$ \\
$\mathrm{S} 0,5 \%+4 \% \mathrm{OF}$ & 225 & 342 & 118 & $0,848^{\mathrm{b}}$ & $1264^{\mathrm{b}}$ & $6,8^{\mathrm{b}}$ \\
$\mathrm{S} 0,5 \%+3,5 \% \mathrm{OF}$ & 225 & 338 & 113 & $0,813^{\mathrm{b}}$ & $1389^{\mathrm{a}}$ & $7,8^{\mathrm{a}}$ \\
S0,5\%+4,5\%OF & 223 & 347 & 126 & $0,905^{\mathrm{a}}$ & $1215^{\mathrm{b}}$ & $6,1^{\mathrm{b}}$ \\
\hline CV $(\%)$ & -- & -- & -- & 3,0 & 22,0 & 18,9 \\
\hline
\end{tabular}

a,b,c Médias seguidas de mesma letra na coluna, não diferem pelo teste de Tukey a $5 \%$ de probabilidade. $\mathrm{SS}+4 \% \mathrm{OF}$ - novilhos sem suplementação e oferta de forragem de 4\% do PC; S0,5\% + 4\%OF - novilhos suplementados com concentrado em $0,5 \%$ do $\mathrm{PC}$ e oferta de forragem de $4 \%$ do $\mathrm{PC}$; S0,5\% $+3,5 \% \mathrm{OF}$ novilhos suplementados com concentrado em $0,5 \%$ do PC e oferta de forragem de 3,5\% do PC e S0,5\%+ $4,5 \% \mathrm{OF}$ - novilhos suplementados com concentrado em $0,5 \%$ do PC e oferta de forragem de $4,5 \%$ do PC.

Segundo Porto et al. (2009) animais frequentemente respondem à suplementação proteica durante a estação das águas, com ganhos adicionais de 200 a $300 \mathrm{~g}$. Isso pode não ser significativo quando se compara apenas o ganho de peso com o custo do suplemento múltiplo, principalmente em épocas em que o custo do suplemento é alto, mas pode causar grande impacto no sistema de produção como um todo. A desocupação de áreas para o diferimento das pastagens e o uso destas por categorias de animais mais jovens e eficientes em converter alimento em produto animal possivelmente seriam uma das maiores vantagens da suplementação nas águas.
Ao comparar os três tratamentos que receberam suplementação protéicaenergética, observa-se diferença significativa $(\mathrm{P}<0,05)$ para o ganho de peso médio diário (GMD) (Tabela 6). Inferindo-se que a diferença no GMD se deve principalmente a oferta de forragem, pois se verifica pelo peso vivo dos animais que o consumo de suplemento concentrado foi muito semelhante entre os tratamentos.

Moretti et al. (2011) avaliando o efeito da suplementação $(0,3 \%$ do peso corporal) no desempenho de novilhas manejadas em pastagem de Brachiaria Brizantha cv. Marandu, observaram ganhos superiores para os animais suplementados $(0,700 \mathrm{~kg} / \mathrm{dia})$ em comparação aos 
Rev. Bras. Saúde Prod. Anim., Salvador, v.16, n.1, p.36-46 jan./mar., 2015 http://www.rbspa.ufba.br

animais que não receberam suplementação $(0,587 \mathrm{~kg} / \mathrm{dia})$.

A maior oferta de forragem pode ter influenciado positivamente na seletividade e consumo de forragem, possibilitando maior aporte de nutrientes e ganho de peso. Trabalhando com capim marandu nas alturas de 15 , 25 e $35 \mathrm{~cm}$ (baixa, média e alta oferta de forragem), Casagrande et al. (2011) verificaram que em baixa oferta de forragem o tempo despendido com pastejo foi de 7,3 horas, seguido de 6,4 horas e 5,5 horas, para média e alta oferta, respectivamente. Assim, verifica-se que em alta oferta de forragem a capacidade de selecionar e ingerir matéria seca ocorre mais facilmente, menor tempo gasto na atividade de pastejo, o que poderá refletir positivamente no desempenho animal individual. Com relação ao consumo de forragem Paula et al. (2012) cita que a maior oferta de forragem aumenta a ingestão de matéria seca, desde que essa maior oferta de forragem não ocorra com redução na relação folha:colmo. Assim, é função do manejo do pastejo adequar a frequência e intensidade de desfolhação para que o animal possa colher forragem com idade fisiológica adequada, evitando o acúmulo de tecidos lignificados que correlacionam-se negativamente com os teores de proteína bruta e digestibilidade in vitro da matéria seca (REIS et al., 2012).

O uso de suplementação protéicaenergética para animais sob pastejo, além do aumento no desempenho individual possibilita incremento na produção por área. Observa-se diferenças no ganho de peso vivo/ha $(\mathrm{P}<0,05)$ com ganhos de 865, $1.264, \quad 1.389$ e $1.215 \mathrm{~kg} / \mathrm{ha}$ para os tratamentos SS $+4 \% \mathrm{OF}, \mathrm{S} 0,5 \%+4 \% \mathrm{OF}$, $\mathrm{S} 0,5 \%+3,5 \% \mathrm{OF}$ e $\mathrm{S} 0,5 \%+4,5 \% \mathrm{OF}$, respectivamente (Tabela 6). Com aumento no ganho de peso em $46 \%$ entre $\mathrm{SS}+4 \% \mathrm{OF}$ e S0,5\%+4\%OF, em $61 \%$ entre SS $+4 \% \mathrm{OF}$ e $\mathrm{S} 0,5 \%+3,5 \% \mathrm{OF}$ e em $41 \%$ entre $\mathrm{SS}+4 \% \mathrm{OF}$ e $\mathrm{S} 0,5 \%+$ $4,5 \% \mathrm{OF}$.

Ao comparar os tratamentos com 4,0\% de oferta de forragem e uso ou não de $0,5 \%$ de suplementação protéicaenergética, constata-se que o uso de suplementação protéica-energética para bovinos em pastagem, além de incrementar o ganho de peso vivo individual, possibilita aumentar o ganho de peso por área (46\%). Contudo, o uso de suplementação deve ser realizado com critério para que não ocorra um efeito substitutivo da forragem pelo suplemento concentrado ofertado a ponto de comprometer o sistema de produção. De forma geral, o efeito substitutivo obtido com a suplementação é diretamente proporcional à qualidade da forragem (MINSON, 1990). Contudo, seria desejável, havendo substituição, que esta assumisse valores inferiores a $1,0 \mathrm{~g} / \mathrm{g}$, observando-se redução do consumo de pasto, mas ampliação do consumo total (COSTA et al., 2011).

Um possível indicativo de que a forragem está sendo substituída pela suplementação protéica-energética ofertada é o aumento na taxa de lotação, em função das sobras de forragens que leva a inserir mais animais na área para manter a disponibilidade de forragem adequada. Dessa forma, ainda em relação aos tratamentos que ofertaram $4,0 \%$ de oferta de forragem, com ou sem suplementação, pode-se inferir que de forma geral não houve um efeito substitutivo expressivo, pois não foi observada diferenças entre estes dois tratamentos na taxa de lotação (Tabela 6). Sendo um indicativo que a oferta de suplementação protéica-energética de $0,5 \%$ do peso vivo foi adequada por aumentar o desempenho individual e por área. 
Rev. Bras. Saúde Prod. Anim., Salvador, v.16, n.1, p.36-46 jan./mar., 2015 http://www.rbspa.ufba.br ISSN 15199940

A oferta de forragem em 3,5\% do peso vivo mais a suplementação protéicaenergética em $0,5 \%$ do peso vivo proporcionou o maior ganho por área $(1.389 \mathrm{~kg} / \mathrm{ha})$ e a maior taxa de lotação $(7,8 \mathrm{UA} / \mathrm{ha}) \quad(\mathrm{P}<0,05)$. Essa taxa de lotação é compatível a encontrada por Fernandes et al. (2010) que avaliaram animais F1 (Nelore + Blonde D‘Aquitaine) em pastejo rotacionado de capim marandu sendo suplementados em $0,6 \%$ do peso vivo, onde observaram uma taxa de lotação de 7,1 UA/ha no período das águas. De acordo com os autores essa taxa de lotação é compatível com a adubação planejada que possibilitou alta produção de MS.

A definição da melhor oferta de forragem vai depender do objetivo da recria de bovinos. Se a recria visa o desempenho individual, a oferta de forragem em $4,5 \%$ do peso vivo e mais suplementação protéica-energética em $0,5 \%$ do peso vivo seria a mais indicada. Se o objetivo for maximizar a produção por área, a oferta de forragem em $3,5 \%$ do peso vivo e mais uma suplementação protéica-energética de $0,5 \%$ do peso vivo deve prevalecer.

De acordo com Reis et al. (2012) animais na recria alocados em pastos de menor oferta de forragem, demoraram mais no confinamento quando comparado com animais que vieram da recria em pastos maior oferta de forragem. Portanto, manter os animais em pastos com maior altura na recria pode diminuir o tempo de confinamento, o que reduz o custo com essa fase. Entretanto, sistemas, com menor oferta de forragem, podem priorizar o ganho por área.

Assim a pastagem de Brachiaria brizantha cv. Marandu manejada e adubada equilibradamente possibilitou alta produção de matéria seca com composição química adequada que associada a suplementação potencializa o ganho de peso individual e por área.

\section{AGRADECIMENTOS}

A Fapemig, pelo apoio financeiro para a realização deste trabalho.

\section{REFERÊNCIAS}

BRAGA, G.J.; PEDREIRA, C.G.S.; HERLING, V.R.; LUZ, P.H.C.; LIMA, C.G.; Sward structure and herbage yield of rotationally stocked pastures of 'marandu' palisadegrass [Brachiaria brizantha (a.rich.) Stapf] as affected by herbage allowance. Scientia Agricola, v.63, n.2, p.121-129, 2006.

CASAGRANDE, D.R.; AZENHA, M.V.; VALENTE, A.L.S.; VIEIRA, B.R. MORETTI, M.H.; RUGGIERI, A.C.; BERCHIELLI, T.T.; REIS, R.A. Canopy characteristics and behavior of Nellore heifers in Brachiaria brizantha pastures under different grazing heights at a continuous stocking rate. Revista

Brasileira de Zootecnia, v.40, n.11, p.2294-2301, 2011.

COSTA, V.A.C.; DETMANN, E.; PAULINO, M.F.; VALADARES FILHO, S.C.; CARVALHO, I.P.C.; MONTEIRO, L.P. Consumo e digestibilidade em bovinos em pastejo durante o período das águas sob suplementação com fontes de compostos nitrogenados e de carboidratos. Revista Brasileira de Zootecnia, v.40, n.8, p.1788-1798, 2011. 
Rev. Bras. Saúde Prod. Anim., Salvador, v.16, n.1, p.36-46 jan./mar., 2015 http://www.rbspa.ufba.br ISSN 15199940

DIXON, R.M.; STOCKDALE, C.R. Associative effects between forages and grains: consequences for feed utilization. Australian Journal Agricultural Research, v.50, n.5, p.757-773, 1999.

EMPRESA DE PESQUISA

AGROPECUÁRIA DE MINAS

GERAIS/ INSTITUTO NACIONAL DE METEREOLOGIA - EPAMIG/INMET.

Dados Climáticos de 2010 e 2011.

Uberaba, 2014.

EUCLIDES, VP.; MACEDO, M.C.M.;

VALLE, C.B.; BARBOSA, R.A.; GONÇALVES, W.V. Produção de forragem e características da estrutura do dossel de cultivares de Brachiaria brizantha sob pastejo. Pesquisa Agropecuária Brasileira, v.43, n.12, p.1805-1812, 2008.

FERNANDES, L.O.; REIS, R.A.; PAES, J.M.V. Efeito da suplementação no desempenho de bovinos de corte em pastagem de Brachiaria brizantha cv. Marandu. Revista Ciência e Agrotecnologia, v.34, n.1, p.240-248, 2010 .

LAZZARINI, I.; DETMANN, E.; SAMPAIO, C.B.; PAULINO, M.F.; VALADARES FILHO, S.C.; SOUZA, M.A.; OLIVEIRA, F.A. Intake and digestibility in cattle fed low-quality tropical forage and supplemented with nitrogenous compounds. Revista Brasileira de Zootecnia, v.38, n.10, p.2021-2030, 2009.

MATHIS, C.P.; COCHRAN, R.C.; HELDT, J.S.; WOODS, B.C.; ABDELGADIR, I. E.; OLSON, K.C.; TITGEMEYER, E.C.; VANZANT, E.S. Effects of supplemental degradable intake protein on utilization of medium-to lowquality forages. Journal of Animal Science, v.78, n.1, p.224-232, 2000.
MINSON, D.J. Forage in ruminant nutrition. New York: Academic Press, 1990. 483p.

MOORE, J.E.; BRANT, M.H.; KUNKLE, W.E.; HOPKINS, D.I. Effects of supplementation on voluntary forage intake, diet digestibility, and animal performance. Journal of Animal Science, v.77, p.122-135, 1999. Suppl. 2.

MORETTI, M.H.; REIS, R.A.; CASAGRANDE, D.R., RUGGIEIRI, A.C.; OLIVEIRA, R.V.; BERCHIELLI, T.T. Suplementação protéica energética no desempenho de novilhas em pastejo durante a fase de terminação. Revista Ciência e Agrotecnologia, v.35, n.3, p.606-612, 2011.

PAULA, C.C.L., EUCLIDES, V.P.B., MONTAGNER, D.B., LEMPP, B.; DIFANTE, G.S.; CARLOTO, M.N. Estrutura do dossel, consumo e desempenho animal em pastos de capim-marandu sob lotação contínua. Arquivo Brasileiro de Medicina Veterinária e Zootecnia, v.64, n.1, p.169-176, 2012.

PAULINO, M.F.; MORAES, E.H.B.K.; ZERVOUDAKIS, J.T.;

ALEXANDRINO, E.; FIGUEIREDO,

D. M. Fontes de Energia em

Suplementos Múltiplos de Auto-

Regulação de Consumo na Recria de Novilhos Mestiços em Pastagens de Brachiaria decumbens durante $o$ Período das Águas. Revista Brasileira de Zootecnia, v.34, n.3, p.957-962, 2005.

POPPI, D.P.; McLENNAN, S.R. Protein and energy utilization by ruminants at pasture. Journal of Animal Science, v.73, p.278-290, 1995. Suppl. 2. 
Rev. Bras. Saúde Prod. Anim., Salvador, v.16, n.1, p.36-46 jan./mar., 2015 http://www.rbspa.ufba.br

PORTO, M.O.; PAULINO, M.F.;

VALADARES FILHO, S.C.; SALES,

M.F.L.; LEAO, M.I.; COUTO, V.R.M.

Fontes suplementares de proteína para novilhos mestiços em recria em pastagens de capim-braquiária no período das águas: desempenho produtivo e econômico. Revista Brasileira de Zootecnia, v.38, n.8, p.1553-1560, 2009.

REIS, R.A.; RUGGIERI, A.C.; CASAGRANDE, D.R.; PÁSCOA, A.G. Suplementação da dieta de bovinos de corte como estratégia do manejo das pastagens. Revista Brasileira de Zootecnia, v.38, p.147-159, 2009.

REIS, R.A.; RUGGIERI, A.C.; OLIVEIRA, A.A.; AZENHA, M.V.; CASAGRANDE, D.R. Suplementação como Estratégia de Produção de Carne de Qualidade em Pastagens Tropicais.

Revista Brasileira de Saúde e Produção Animal [online], v.13, n.3, p.642-655, 2012.

SILVA, D.J.; QUEIROZ, A.C. Análise de alimentos: métodos químicos e biológicos. Viçosa, MG: Universidade Federal de Viçosa, 2006. 235p.

Van SOEST, P.J. Nutritional ecology of the ruminant. 2th ed. Ithaca: Cornell University Press, 1994. 476p.

Data de recebimento: $30 / 06 / 2014$

Data de aprovação: 18/12/2014 